\title{
Towards Sustainable Power Generation Using Solar Chimney
}

\author{
Mahmoud Bady \\ Department of Energy Resources Engineering, Egypt-Japan University of Science and Technology (E-JUST), New \\ Borg El-Arab City, Alexandria, Egypt \\ Email: mahmoud.bady@ejust.edu.eg
}

Received 1 April 2015; accepted 16 April 2015; published 21 April 2015

Copyright (C) 2015 by author and OALib.

This work is licensed under the Creative Commons Attribution International License (CC BY). http://creativecommons.org/licenses/by/4.0/

(c) (i) Open Access

\begin{abstract}
According to the strategic re-urbanization of the Egyptian population from the densely populated areas, numerous new settlements with residential housing areas will be set up in the countryside in the near future. The scheduled areas are mainly situated in hot arid areas. The use of the high temperature air in these areas in electricity generation for the residential houses is quite important, since the success of the re-urbanization project depends mainly on providing urban buildings with a suitable level of infrastructure and facilities. Solar chimney power plant (SCPP) is one of the promising power generation facilities that use solar energy for electricity production. It is a solar thermal power plant that utilizes a combination of solar air collector and central updraft tube to generate a solar induced convective flow which drives pressure staged turbines to generate electricity. In this paper, a description of the functional principle of the SCPP components is presented and some results from designing a medium scale unit using simple mathematical model are given.
\end{abstract}

\section{Keywords}

Solar Chimney, Sustainability, Solar Energy, Power Generation

Subject Areas: Environmental Sciences, Mechanical Engineering

\section{Introduction}

The growing demand in energy and concerns about depletion of natural resources and global warming has led states worldwide to consider alternatives to the use of fossil fuel for energy production. Several countries especially in Europe have already increased their renewable energy share by about $6 \%-10 \%$, and it is expected to increase further to $20 \%$ by year 2020. For Egypt excellent resources of solar energy exist. The local demand for energy and electricity is rapidly growing at the same time where the two major energy sources of the country, namely oil and natural gas, are dewendling. 
Egypt strategy approved in February 2008, aims to increase the contribution of renewable energies by 20\% of the total electricity generation by the year 2020. The country sees renewables as an important potential industry worthy of development, and one which plays well to its comparative advantage of a large, well educated and comparatively low-cost workforce, and to its strong trade links throughout the Middle East and North African regions, as well as Europe and United States. Need for promoting renewables for power generation arises, also, from the social perspective of energy within the context of sustainable development.

Solar chimney power plant (SCPP) is one of the promising power generation facilities that use solar energy for electricity production. It is a solar thermal power plant utilizing a combination of solar air collector and central updraft tube to generate a solar induced convective flow which drives pressure staged turbines to generate electricity.

There are three conditions that make Egypt a very favorable country for this type of solar power plants. First, Egypt location on the world map makes it an advantageous place for benefiting from solar energy. It lies in the North-African Sun Belt with flat desert topography and perennially clear skies favorable to commercial solar technologies [1] [2]. Second, the annual solar radiation intensity averages $6.0 \mathrm{kWh} / \mathrm{m}^{2} /$ day, about $130 \%$ higher than Germany; yet per capita use of solar technologies is less than $10 \%$ of Germany's. Finally, there are large suitably flat areas of land available either in Sinai, east desert, west desert or in Upper Egypt [1] [2]. These regions have suitable sites for building large-scale SCPPs.

Many attempts have been carried out to evaluate the performance of SCPPs. Some researchers such as Mohamed H. [3] [4] and Mohamed A. (2013) [5] used simple mathematical models to study the effects of geometrical and meteorological parameters on the SCPP performance. Other researchers such as Hermann et al. [6] and Ehsan et al. [7] carried out CFD simulations to simulate buoyancy-driven flow and heat transfer characteristics through the system. However, the application of solar chimney as a promising technique for future electricity demands of Egypt has seldom reported. Accordingly, the present paper sheds the light on the solar chimney power plant as a promising technique for generation electricity using solar energy in Egypt. A description of the functional principle of the SCPP components is presented at first. Then, some results from a simple mathematical analysis for the SCPP are given.

\section{Solar Radiation Intensity in Egypt}

Egypt is one of the sunbelt countries that enjoys one of the largest potentials of solar energy applications as shown in the Solar Atlas map [8] presented in Figure 1. According to Figure 2, the global annual average solar radiation in Egypt varies from 5.0 to $7.0 \mathrm{kWh} / \mathrm{m}^{2}$ and the sunshine duration ranges between 9 and $11 \mathrm{~h} /$ day from North to South with very few cloudy days. The regions of high solar intensity are located south Egypt, where the solar intensity ranges between $6-7 \mathrm{~kW} / \mathrm{m}^{2}$.day. The solar intensity decreases in the directions to the north, where it has values lower than $5.4 \mathrm{~kW} / \mathrm{m}^{2}$.day along the north borders of the country.

In Europe, for example in Italy, the solar radiation varies from 3.6 to $4.7 \mathrm{kWh} / \mathrm{m}^{2} /$ year, with average sunshine hours of 6 to 7.5 h/day. In Germany, the solar radiation intensity ranges from 2.3 to $3.0 \mathrm{kWh} / \mathrm{m}^{2} /$ year, with average sunshine hours of 4.5 to $5.1 \mathrm{~h} /$ day.

\section{A Simple Mathematical Model for SCPP}

A schematic diagram of the solar chimney power plant is presented in Figure 3. A simplified model is used to describe the entire power plant including the three major components, which are the solar collector, the chimney, and the wind turbine. In order to simplify the problem, some assumptions are adopted as follows:

1) The height of the collector from the ground was considered large enough to disregard the pressure drop in the collector section. However, this assumption deviates in the district near the chimney inlet.

2) Radiation to the chimney is ignored since the surface area of the collector is much larger than the surface area of the chimney. Therefore, heat transfer equation is only considered for the collector. The temperature change across the chimney is small, hence $T_{4}=T_{3}$.

3) The process across the turbine is assumed to be isentropic (i.e. reversible and adiabatic).

4) Heat transfer from the system to the surrounding was ignored and only heat transfer from the surrounding to the collector is considered.

5) The analysis is based on steady flow assumption which is an approximation because solar radiation is transient in nature. 


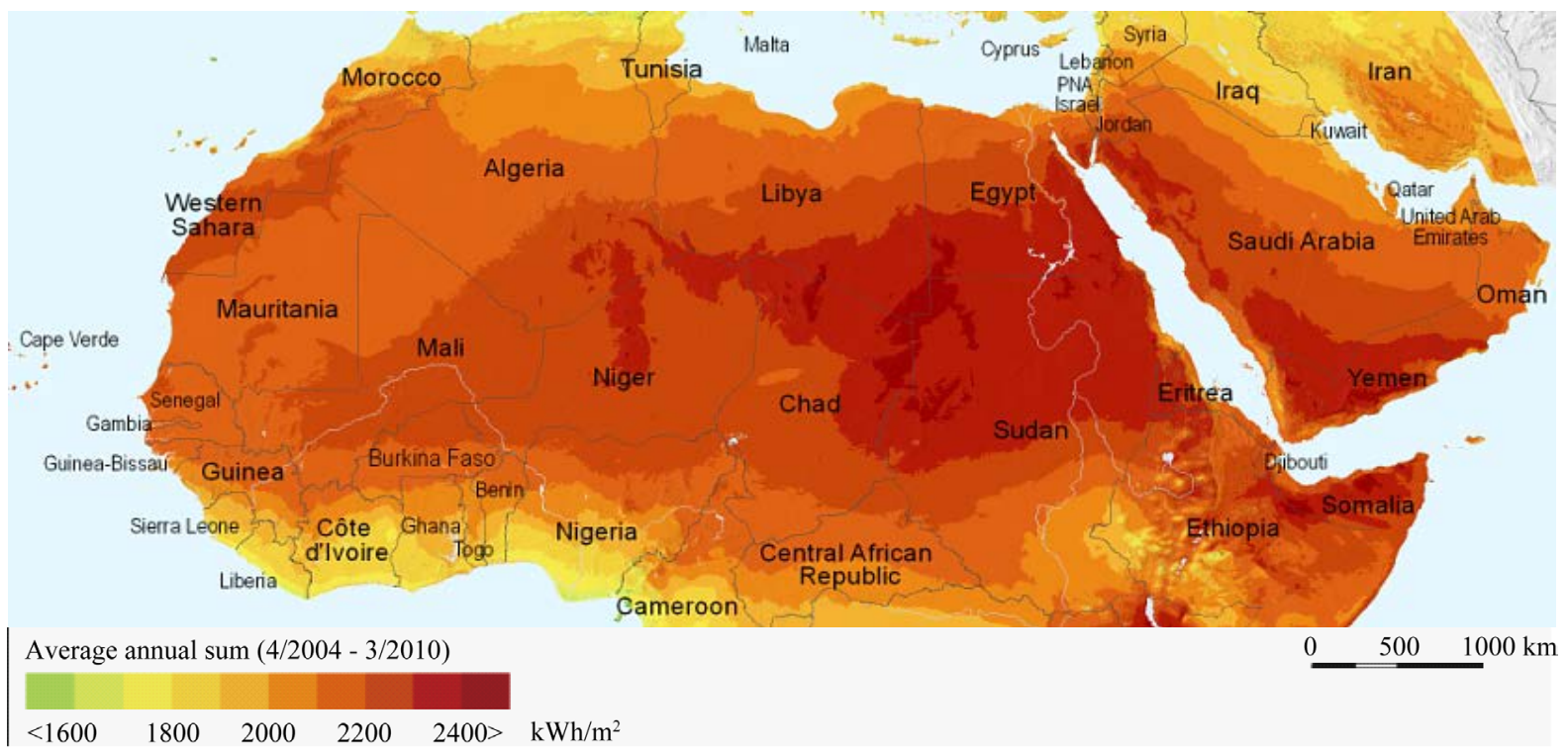

Figure 1. Average solar radiation of the Arab world [8].

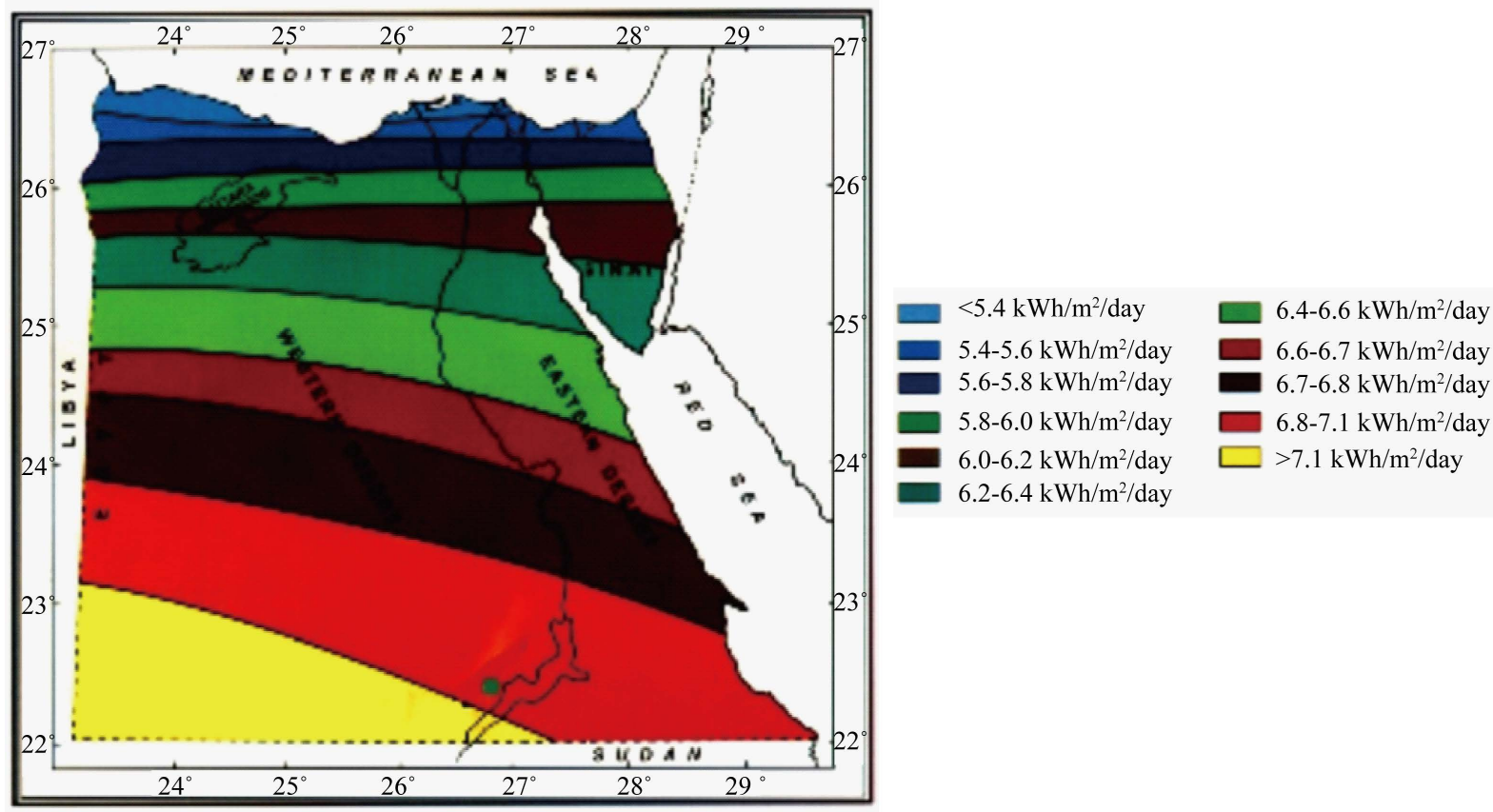

Figure 2. Distribution of solar energy generation potentials in Egypt [1].

6) The flow is incompressible across the chimney since Mach number is below 0.3.

7) Uniform solar heat flux averaged over the day period is used in the calculation.

\subsection{The Collector}

The mass flow rate across the collector is conserved and pressure drop is neglected. $p_{2}=p_{1}$ as explained in the assumption. The energy equation for the collector section is used to calculate the mass flow rate inside the solar chimney as follows:

$$
\dot{m}=\frac{q^{\prime \prime} A_{c}}{h_{2}-h_{1}}
$$




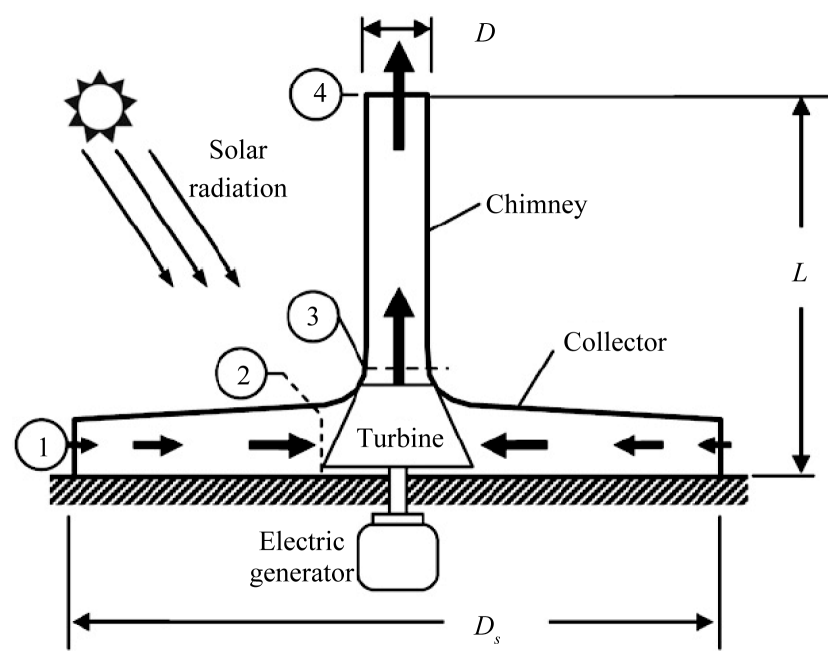

Figure 3. A schematic diagram of solar chimney power plant.

where $\dot{m}$ is the air mass flow rate $(\mathrm{kg} / \mathrm{s}), q^{\prime \prime}$ is the absorbed solar radiation excluding the thermal losses $\left(\mathrm{W} / \mathrm{m}^{2}\right), A_{c}$ is the collector area $\left(\mathrm{m}^{2}\right)$, and $h_{1}$ and $h_{2}$ are the enthalpy of air at collector inlet and outlet, respectively $(\mathrm{J} / \mathrm{kg} \cdot \mathrm{K})$.

\subsection{The Turbine}

Across the turbine, the pressure head is related to turbine head as shown in Equation (2). Entropy across the turbine is constant hence the pressure expansion is assumed to be isentropic.

$$
\begin{aligned}
& p_{3}=p_{2}-\rho_{2} g H_{T} \\
& s_{3}=s_{2}
\end{aligned}
$$

where $H_{T}$ is the turbine head (m), $g$ is the gravitational acceleration $\left(\mathrm{m} / \mathrm{s}^{2}\right), \rho_{2}$ is the air density at $T_{2}$, and $s$ is the specific entropy $(\mathrm{J} / \mathrm{kg} \cdot \mathrm{K})$.

The density of air across the turbine is assumed to be constant since the wind speed is not high, compared to the speed of sound, and there is no heat added or removed across the turbine. In addition, the pressure drop across the turbine is very small since the study assumes the use of a one stage wind turbine.

\subsection{The Chimney}

The air draft in the chimney is modeled using the following modified Bernoulli equation [3] [4] [9]:

$$
\frac{p_{3}-p_{4}}{g \rho_{4}}=\left(z_{4}-z_{1}\right)_{\text {Gravity Head }}+\frac{\dot{m}^{2}}{2 g A_{3}^{2} \rho_{4}^{2}}\left(f \frac{H_{\text {chimney }}}{D_{3}}+K_{\text {in }}+K_{\text {out }}\right)_{\text {Friction Head }}
$$

where $f$ is the friction factor, $D_{3}$ is the chimney diameter (m), $H_{\text {chimney }}$ is the chimney height (m), $K_{\text {in }}$ and $K_{\text {out }}$ are loss coefficients at inlet and outlet sections respectively.

From the second assumption introduced in Section 3.1, the temperature change across the chimney is small, which means:

$$
T_{4} \approx T_{3}
$$

For standard atmosphere and using Figure 1, the atmospheric pressure change across the solar chimney is written as follows [4]:

$$
p_{4}=p_{1}\left(1-\frac{\beta}{T_{1}} H_{\text {chimney }}\right)^{(g / \beta R)}
$$

where $T_{1}$ is the air temperature at collector inlet $(\mathrm{K}), \beta$ is the laps rate $(\mathrm{K} / \mathrm{m}) ; p$ is the pressure $(\mathrm{Pa})$, and $R$ is the 
air gas constant $(\mathrm{J} / \mathrm{kg} \cdot \mathrm{K})$.

\subsection{Performance Parameters of the SCPP}

The expected turbine work is calculated according to the equation:

$$
w_{t}=h_{2}-h_{3}
$$

where $h_{2}$ and $h_{3}$ are the enthalpy at turbine inlet and outlet, respectively.

Without turbine, a maximum flow speed of $v_{\text {tower,max }}$ is achieved and the whole pressure difference is used to accelerate the air and is thus converted into kinetic energy. Using the Boussinesq approximation [10], the speed reached by free convection currents can be expressed as:

$$
v_{\text {tower, } \max }=\sqrt{2 g \times H_{\text {chimney }} \times \frac{\Delta T}{T_{1}}}
$$

where $\Delta T$ is the temperature rise between collector inlet and outlet; $T_{3}-T_{1}$.

The second-law efficiency of the solar chimney power plant is defined as turbine extracted work over the available work as follows:

$$
\eta_{I I}=\frac{w_{t}}{\Delta \psi_{1-4}}=\frac{h_{2}-h_{3}}{\left(h_{4}-h_{1}\right)-T_{1}\left(s_{4}-s_{1}\right)+g\left(z_{4}-z_{1}\right)}
$$

Finally, the overall plant efficiency is calculated as follows:

$$
\eta_{\text {plant }}=\frac{\dot{W_{t}}}{\dot{Q}}=\frac{\dot{m}\left(h_{2}-h_{3}\right)}{q^{\prime \prime} \times A_{c}}
$$

A SCPP model with the specifications mentioned in Table 1 is considered to estimate the performance parameters. These geometrical data are taken from previous published work [4].

The above set of equations have the unknowns: $\dot{m}, h_{2}, p_{3}, s_{3}, \rho_{4}$ and $T_{4}$. In order to solve theses equations, an iteration technique using a FORTRAN-language program was carried out so that the SCPP performance parameters could be predicted under different geometrical parameters and operating conditions.

\section{Results and Analysis}

Figures 4-9 show the effects of different geometry parameters on the performance of the SCPP. These parameters are: chimney height, chimney diameter, and collector diameter.

\subsection{Effect of Geometry Parameters on the SCPP Performance}

Figure 4 shows that the power generation and maximum air velocity in the chimney are highly dependent on the

Table 1. Technical and geometrical data used in SCPP performance calculations [4].

\begin{tabular}{cc}
\hline Chimney height & $445 \mathrm{~m}$ \\
\hline Chimney diameter & $54 \mathrm{~m}$ \\
Collector diameter & $1110 \mathrm{~m}$ \\
Solar intensity & $300 \mathrm{~W} / \mathrm{m}^{2}$ (for Aswan-Egypt) \\
Air temperature & $303 \mathrm{~K}$ \\
Turbine head & $200 \mathrm{~m}$ \\
Laps rate & $6.5 \mathrm{~K} / \mathrm{km}$ \\
$K_{\text {in }}$ & 0.5 \\
$K_{\text {out }}$ & 1.0 \\
Friction factor & 0.01 \\
\hline
\end{tabular}




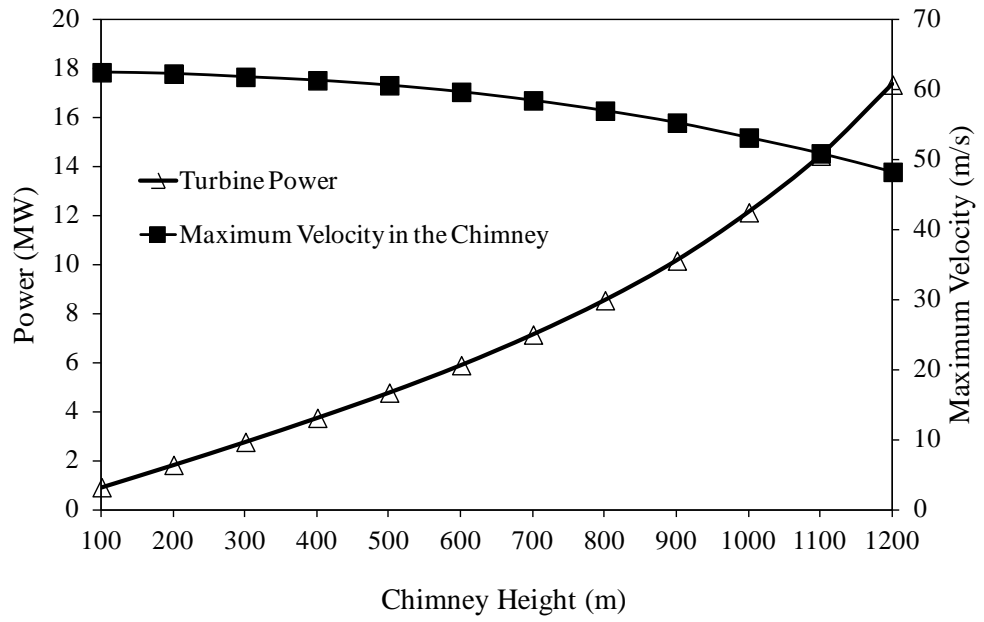

Figure 4. The power generated and the maximum velocity in the chimney versus the chimney height.

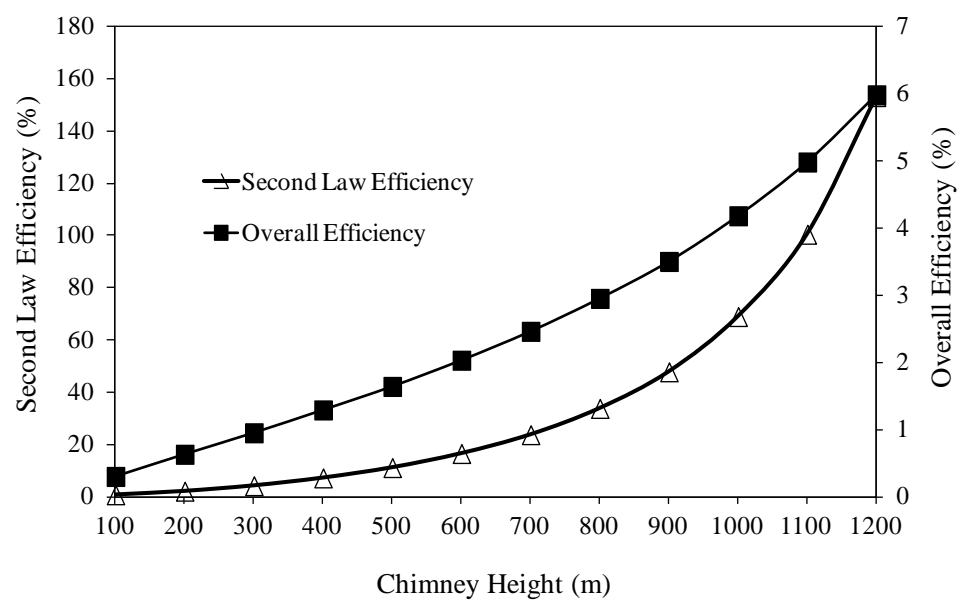

Figure 5. The overall plant efficiency and the second law efficiency versus the chimney height.

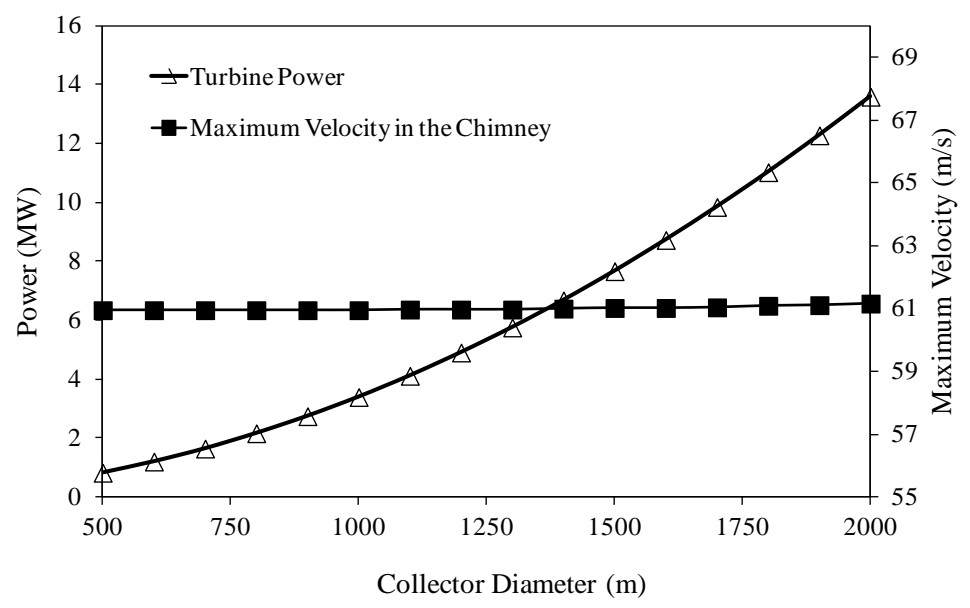

Figure 6. The power generated and the maximum velocity in the chimney versus the collector diameter. 


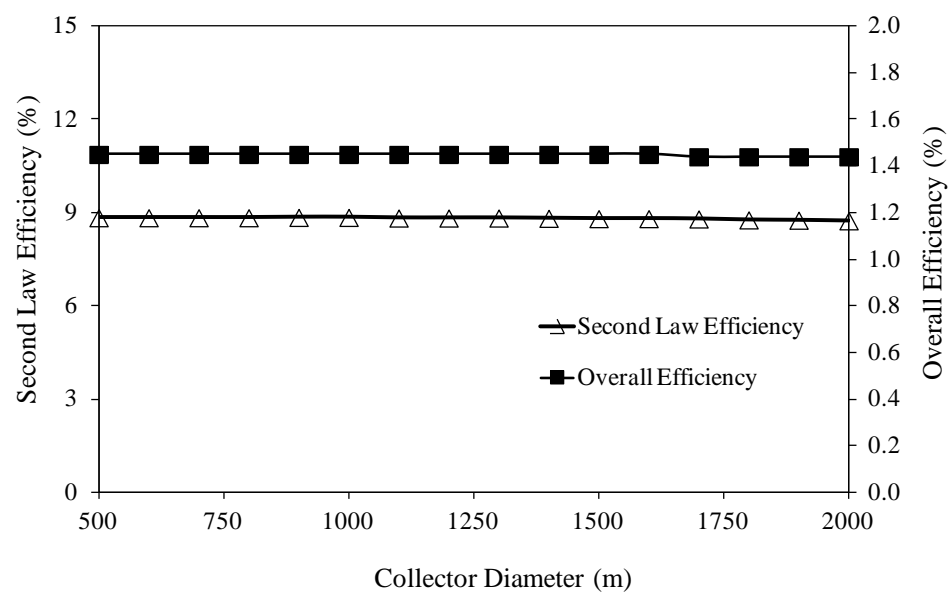

Figure 7. The overall plant efficiency and the second law efficiency versus the collector diameter.

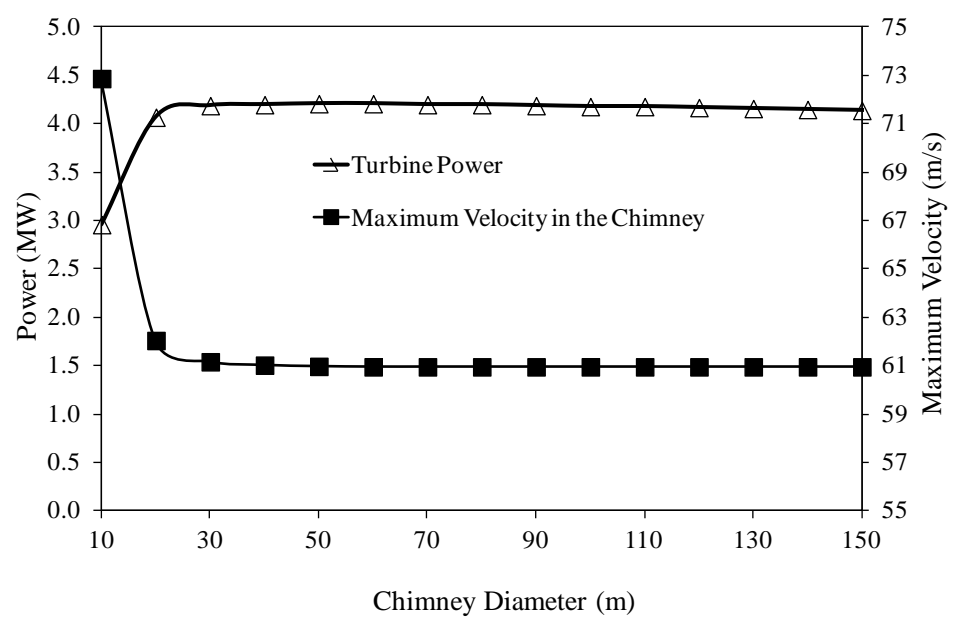

Figure 8 . The power generated and the maximum velocity in the chimney versus the chimney diameter.

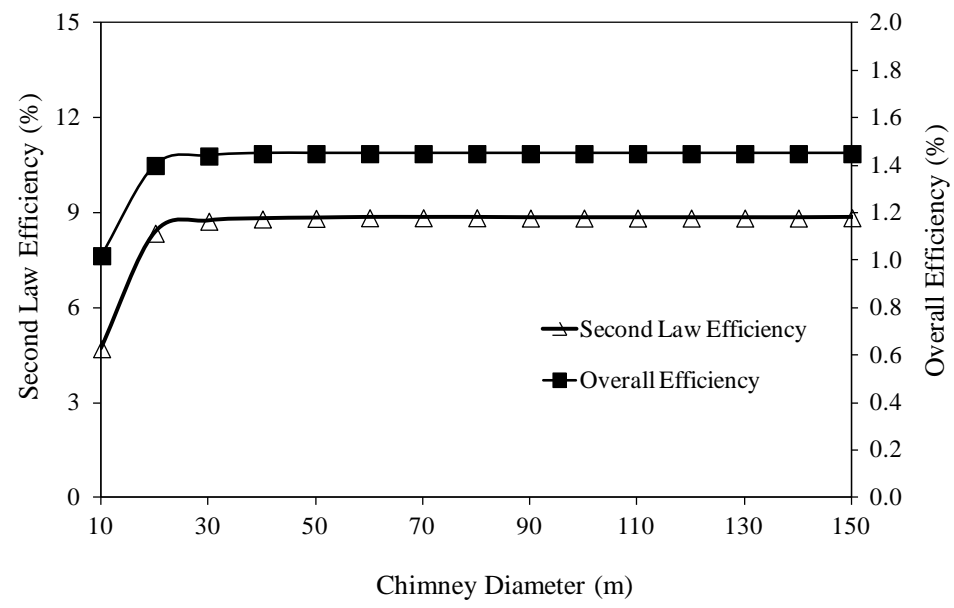

Figure 9. The overall plant efficiency and the second law efficiency versus the chimney diameter. 
height of the chimney and that; as chimney height increases, one expects that power output increases. The increased chimney height decreases the maximum velocity in the chimney, which in turn decreases the friction losses. Since the friction losses are proportional to the velocity [9], the decrease in velocity would cause lower losses and hence increase the second-law efficiency.

Another important point is that; the higher the chimney means higher driving force which is the buoyancy difference. The rate of increase in this driving force is higher than the friction losses due to chimney height; therefore the second-law efficiency is expected to increase with the chimney height, as indicated in Figure 5. Similarly; the effect of chimney height on the overall plant efficiency is obviously positive even its value is quite low.

The effect of collector diameter on solar chimney is shown in Figure 6, Figure 7. These figures show that; the collector diameter has a prominent effect on the generated power, while it has no considerable effects on the other three parameters. As collector diameter increases, the amount of output power increases and the maximum air velocity inside the chimney is almost constant. On the other hand, the second-law efficiency and the overall efficiency moderately decreases since as collector diameter increases the driving buoyancy force increases causing a higher velocity inside the chimney which causes higher friction losses.

The effect of chimney diameter on the solar chimney is shown in Figure 8, Figure 9. The figures show that the chimney diameter has a prominent effect on the generated power, mainly when chimney diameter is below a critical value $(=20 \mathrm{~m})$. The critical diameter depends on Reynolds number and boundary layer thickness. If chimney diameter is larger than the critical diameter value, the effect of chimney diameter is minimal. As chimney diameter increases, the friction losses decrease which decreases as air velocity inside the chimney decreases.

\subsection{Effect of the Solar Radiation Intensity on the SCPP Performance}

This section investigates the effect of the monthly incident solar intensity of Egypt on the SCPP performance if a SCPP with the specifications mentioned in Table 1 is built in Egypt. Table 2 presents the monthly recorded mean of the global solar radiation in Aswan, Egypt. The solar intensity value is averaged over 10 years [8].

Figure 10 shows the monthly variation of the expected power output from a SCPP with the incident global solar radiation. The generated power has a maximum value of 4.8 MW in June at the maximum solar radiation intensity of $333.3 \mathrm{~W} / \mathrm{m}^{2}$. The minimum output power of 2.6 MW occurs in December, where the incident solar radiation has a minimum value of $179.0 \mathrm{~W} / \mathrm{m}^{2}$. These results show that; an average value of $3.8 \mathrm{MW}$ could be obtained from a single unit has the specifications mentioned in Table 1.

\section{Table 2. The monthly recorded mean of the global solar radiation (in $\mathrm{kWh} / \mathrm{m}^{2} / \mathrm{day}$ ) in Egypt [8].}

\begin{tabular}{ccccccccccccccc}
\hline Month & Jan & Feb & Mar & Apr & May & Jun & Jul & Aug & Sep & Oct & Nov & Dec \\
\hline G & 4.6 & 5.6 & 6.5 & 7.3 & 7.4 & 8.0 & 7.8 & 7.4 & 6.6 & 5.7 & 4.8 & 4.3 \\
\hline
\end{tabular}

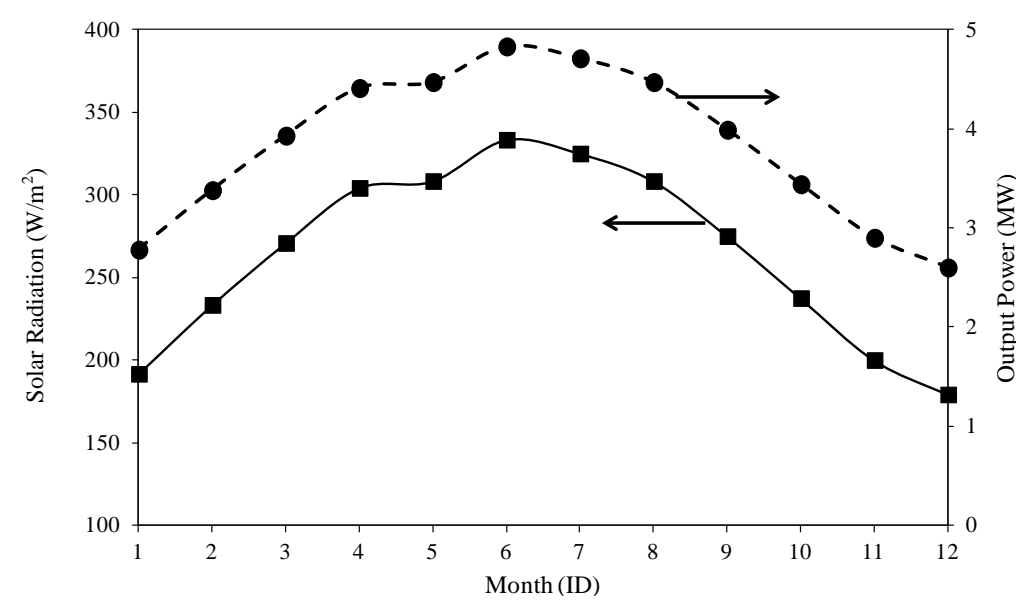

Figure 10. Variation of the expected power generated from the SCPP with the incident global solar radiation in Egypt. 


\section{Conclusion}

This paper presents a simple mathematical model to predict the performance of a solar chimney power plant for different geometry and operating conditions. Four performance parameters were considered in the analysis: turbine power, maximum air velocity inside the chimney, second-law efficiency and the overall plant efficiency. The study results show that, the chimney height and diameter, collector diameter and solar intensity are critical parameters for building a solar chimney power plant. The chimney height has a very strong effect on the second-law efficiency and total generated power. The chimney diameter has a small effect except for very small chimney diameter where friction becomes a dominant factor. The collector diameter has a very small effect on second-law efficiency since the friction losses minimized by the wide inlet area and low average velocity inside the collector. The solar radiation intensity values in Egypt allow the generation of 4.8 MW in summer and 2.6 MW in winter if one medium size SCPP with the specifications mentioned in Table 1 is built in Egypt.

\section{References}

[1] The Egyptian Ministry of Electricity (2011) New Energy and Renewable Energy Authority (NREA) Annual Report 2010-2011.

[2] Solar Atlas. www.solargis.info/

[3] Mohammad, H. (2013) Analysis of Solar Chimney Power Plant Utilizing Chimney Discrete Model. Renewable Energy, 56, 50-54. http://dx.doi.org/10.1016/j.renene.2012.09.047

[4] Mohammad, H. (2011) Analysis of a Solar Chimney Power Plant in the Arabian Gulf Region. Renewable Energy, 36, 2593-2598. http://dx.doi.org/10.1016/j.renene.2010.05.002

[5] Mohamed, A. (2013) Analysis Study of Solar Tower Power Plant and Its Configuration Effects on Its Performance in Iraq (Baghdad City). Modern Applied Science, 7, 55-69.

[6] Hermann, F., Fanlong, M., Ehsan, S. and Andreas, G. (2013) CFD Analysis for Solar Chimney Power Plants. Solar Energy, 98, Part A, 12-22.

[7] Ehsan, G. and Man-Hoe, K. (2014) Three-Dimensional CFD Analysis for Simulating the Greenhouse Effect in Solar Chimney Power Plants Using a Two-Band Radiation Model. Renewable Energy, 63, 498-506.

[8] Alnaser, W., Eliagoubi, B., Al-Kalak, A., Trabelsi, H., Al-Maalej, M. and El-Sayed, M. (2004) First Solar Radiation Atlas for the Arab World. Renewable Energy, 29, 1085-1107. http://dx.doi.org/10.1016/j.renene.2003.10.007

[9] Munson, B., Young, D. and Okiishi, T. (1994) Fundamentals of Fluid Mechanics. 2nd Edition, John Wiley \& Sons, Hoboken.

[10] Jörg, S., Rudolf, B., Wolfgang, S. and Gerhard, W. (2005) Design of Commercial Solar Updraft Tower Systems—Utilization of Solar Induced Convective Flows for Power Generation. Journal of Solar Energy Engineering, 127, 117-124. http://dx.doi.org/10.1115/1.1823493 